\title{
Pollen and spores as a passive monitor of ultraviolet radiation
}

\author{
Wesley T. Fraser ${ }^{1 *}$, Barry H. Lomax ${ }^{2}$, Phillip E. Jardine ${ }^{3}$, William D. Gosling ${ }^{3}$ and Mark A. Sephton ${ }^{4}$ \\ ${ }^{1}$ Geography, Department of Social Sciences, Oxford Brookes University, Oxford, UK \\ ${ }^{2}$ Agriculture and Environmental Science, University of Nottingham, Leicestershire, UK \\ ${ }^{3}$ Department of Environment, Earth and Ecosystems, The Open University, Milton Keynes, UK \\ ${ }^{4}$ Department of Earth Science and Engineering, Imperial College London, London, UK
}

\section{Edited by:}

Valentí Rull, Botanic Institute of Barcelona (CSIC), Spain

Reviewed by:

Mark Bush, Florida Institute of Technology, USA

Simon J. Goring, University of Wisconsin - Madison, USA

*Correspondence:

Wesley T. Fraser, Geography, Department of Social Sciences,

Oxford Brookes University, Gipsy

Lane Campus, Oxford, OX3 OBP, UK

e-mail:wfraser@brookes.ac.uk
Sporopollenin is the primary component of the outer walls of pollen and spores. The chemical composition of sporopollenin is responsive to levels of ultraviolet (UV) radiation exposure, via a concomitant change in the concentration of phenolic compounds. This relationship offers the possibility of using fossil pollen and spore chemistry as a novel proxy for past UV flux. Phenolic compounds in sporopollenin can be quantified using Fourier Transform infrared spectroscopy. The high potential for preservation of pollen and spores in the geologic record, and the conservative nature of sporopollenin chemistry across the land plant phylogeny, means that this new proxy has the potential to reconstruct UV flux over much longer timescales than has previously been possible. This new tool has important implications for understanding the relationship between UV flux, solar insolation and climate in the past, as well as providing a possible means of assessing paleoaltitude, and ozone thickness.

Keywords: ultraviolet radiation, sporopollenin, FTIR, proxy, palynomorph

\section{INTRODUCTION}

Sporopollenin is a recalcitrant biopolymer with resistance to all but the harshest chemical, physical, and biological attacks (Ariizumi and Toriyama, 2011). This highly resistant organic network is the primary constituent of the outer walls (exine) of spores and pollen. Recent research into the composition of sporopollenin has revealed measurable changes in response to exposure to ultraviolet (UV) radiation that occur during the process of spore generation (Lomax et al., 2008; Fraser et al., 2011). The chemical sensitivity of sporopollenin to UV exposure raises the exciting prospect of reconstructing past UV radiation flux using fossil sporomorphs (preserved pollen and spores) (Rozema et al., 1997, 1999, 2001; Watson et al., 2007, 2012; Fraser et al., 2012). Calibration of natural UV-stimulated chemical responses in sporopollenin during growth provides the possibility to use fossil palynomorphs as passive monitors of past UV conditions. Thus the opportunity exists to generate data on UV flux beyond the instrument-monitoring era (beginning in 1924 Farman, 1977) and back into geological time.

\section{THE CHEMICAL BASIS OF A UV PROXY}

Gas chromatography-mass spectrometry (GC/MS) revealed that the structural components liberated from sporopollenin during thermally-assisted chemical degradation (thermochemolysis) fall into two groups; unbranched aliphatic acids (fatty acids), and phenolic compounds (Blokker et al., 2005; Watson et al., 2007) (Figure 1). While GC/MS techniques provide a comprehensive analysis of sporopollenin components, it remains timeconsuming and relatively expensive. The phenolic components within sporopollenin have been shown to readily absorb UV radiation in the UV-B $(280-315 \mathrm{~nm})$ and UV-A $(315-400 \mathrm{~nm})$ wavebands (Rozema et al., 2001; Fraser et al., 2011). UVabsorbing properties provide biochemically-essential internal cell components (i.e., DNA) within sporomorphs some protection against UV damage. Plants apparently regulate production of the phenolic sporopollenin components proportional to UV exposure (Rozema et al., 1997, 1999, 2001; Rozema, 2002).

The two key components of sporopollenin chemsitry are characterized by different functional groups. This means that Fourier Transform infrared (FTIR) spectroscopy can be used to identify the relative abundance of fatty acid and phenolic units within sporopollenin to provide a fast and economical means of accessing biochemical information (e.g., guided by GC/MS data) from sporomorphs (Watson et al., 2007). In comparison with other biogeochemical methods, FTIR also has considerable advantages in terms of sample size required for analysis, preparation time and reduced costs on a per sample basis. FTIR detection of $\mathrm{C}=\mathrm{C}$ bonds within phenolic units results in absorbance of infrared radiation by the spore/pollen samples at $\sim 1510 \mathrm{~cm}^{-1}$ wavenumber (Fraser et al., 2011). Once calibrated, the infrared absorbance band intensity is proportional to the abundance of phenolic components, where it has been shown that the phenolic components of sporopollenin absorb in the UV region of the electromagnetic spectrum (Fraser et al., 2011). Quantification of the intensity of absorbance bands provides a method of tracking of UV-absorbing components within sporopollenin across known UV gradients.

Given the annual production of pollen and spores by plants on a global scale, the chemical response to UV radiation can provide an annual record of incoming solar radiation. In modern and recent samples that are either collected by hand direct from the growing plant, or extracted from herbaria sample this poses no challenge to the temporal position of the sample; the date of 


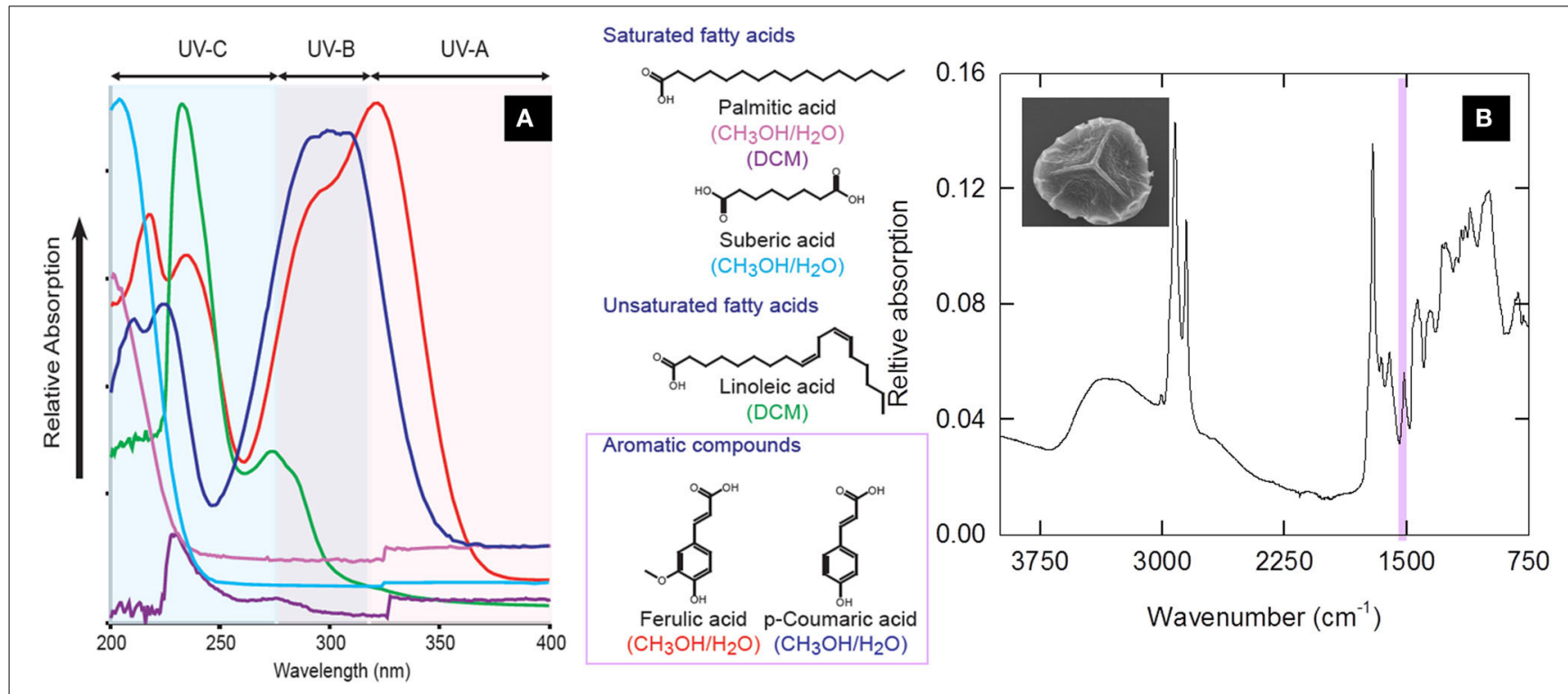

FIGURE 1 | (A) Relative UV-B absorption of chemical standards thought to be constituents of sporopollenin (adapted from Fraser et al., 2011) (B) FTIR trace generated from a Lycopodium clavatum spore; inset,
S.E.M. of a lycopodium spore $(\sim 30 \mu \mathrm{m}$ in diameter). Shaded box identifies the aromatic-based components responsible for protection against UV-B radiation. growth/collection is known. Samples obtained from sedimentary records may possibly have a wider range in temporal position due to the potential for reworking of sediments at the point of deposition (Traverse, 2007). When considering longer time scales from millennia (Willis et al., 2011) to millions of years (Fraser et al., 2012) it is reasonable to assume that the same time frame of annual production and incorporation into sediments takes place.

\section{LONG-TERM PROXY STABILITY AND VIABILITY}

Recent work demonstrates modern (Fraser et al., 2011) and historical spores ranging from 1907 to 2010 collected from herbaria (Watson et al., 2007; Lomax et al., 2008; Willis et al., 2011) yield clear phenolic signals. In addition, geochemical analyses of fossilized palynomorphs suggest the presence of different types of sporopollenin that are distinct along broad phylogenetic groups within the geological record (Hemsley et al., 1995; Vandenbroucke and Largeau, 2007). It has recently become apparent that the recognized phylogenetic variation in sporopollenin form may be due simply to higher-grade, post-deposition, maturation (Watson et al., 2012; Fraser et al., 2014). Maturation experiments under laboratory-simulated conditions, show that modern sporopollenin, in a closed system, undergoes defunctionalisation and repolymerisation to generate a biogeopolymer that closely resembles fossil sporopollenin (Watson et al., 2012; Fraser et al., 2014). As with all laboratory simulations of post-burial maturation certain inherent limitations exist. Specifically whether an increase in temperature appropriately represents an increase in time, and whether the use of a closed system (i.e., no, or limited chemical exchange with surroundings) adequately represents natural open systems where the transfer of chemicals is possible. It is likely, however, that an open system will have limited influence on the final matured sporopollenin material (Gupta et al., 2007). An assertion supported by evidence from laboratory studies which showed that the biogeochemical fingerprint of artificially matured sporopollenin was similar to that of fossil material (Watson et al., 2012; Fraser et al., 2014).

Exquisitely preserved Carboniferous megaspores (c. $310 \mathrm{Ma}$ ) in a cave deposit showed that megaspore sporopollenin bears a strong resemblance to its nearest living relatives (Fraser et al., 2012). These data suggest: (1) that lineages may conserve a single type of sporopollenin across geological time, and (2) differences in the biogeochemistry of spores of minimal maturation may reflect environmental conditions in which the plant grew. Such findings suggest limited changes, if any, in sporopollenin chemistry since the invasion of land by plants $c$. 473-471 Ma (Rubenstein et al., 2010). The geological longevity of the sporopollenin aromatic signal holds great potential for future applications to long-term palynological attempts reconstruction of past UV climatology.

\section{APPLICATIONS OF THE PROXY}

Reconstructions of past UV-B irradiance can provide a more fundamental understanding of controls and feedbacks acting in Earth's systems. Recent work has identified a strong link between solar irradiance and climate. Model simulations linking solar forcing and winter climate variability in the northern hemisphere (Ineson et al., 2011), and paleoclimate data have directly coupled changes in solar activity and atmospheric circulation at the onset of the Homeric grand solar minimum 2800 years ago (Martin-Puertas et al., 2012).

Other environmental parameters covary with UV-B flux, and can therefore be inferred with the new UV-B proxy. For example, UV-B radiation increases with altitude, and this increase has been detected in pollen and spore chemistry. An elevation gradient spanning 650-1980 $\mathrm{m}$ above sea level revealed a doubling in aromatic content within sporopollenin with altitude 
(Watson et al., 2007). UV-B radiation is known to increase by c. $15 \%$ per $1000 \mathrm{~m}$ increase in elevation (Lomax et al., 2012), suggesting a change of 0.150 in the sporopollenin phenolic/OH ratio per $1000 \mathrm{~m}$ in SE Asia (Watson et al., 2007). These findings open up the potential of spore and pollen chemistry to be used as a proxy for past land surface elevation (Lomax et al., 2012). Conversely, UV-B flux decreases with the thickness of the ozone layer (Lomax et al., 2008), which is itself determined by a combination of solar cycles, volcanic aerosols, climate change and anthropogenic depletion (Rozema, 2002). The analysis of pollen and spore chemistry, in combination with other proxy records, therefore offers the opportunity to reveal these forcing mechanisms in the recent geological past (Rozema, 2002; Lomax et al., 2008).

\section{AUTHOR CONTRIBUTIONS}

All authors contributed equally to the work with ideas and discussions. Wesley T. Fraser wrote the paper, Barry H. Lomax drafted the figure and all other authors were involved in revision and editing.

\section{ACKNOWLEDGMENTS}

The authors would like to thank the NERC [NER/A/S/2002/0086], [NE/K005294/1], a NERC studentship and CASE award from Thermo Fisher Scientific [NERC/S/C/2004/13016] and the Leverhulme Trust [ECF/2006/0492] for funding that initiated and facilitated our research into sporopollenin chemistry and palaeo-UV-B reconstructions. Thanks are given to the two reviewers whose comments and suggestions have substantially improved this manuscript.

\section{REFERENCES}

Ariizumi, T., and Toriyama, K. (2011). Genetic regulation of sporopollenin synthesis and pollen exine development. Ann. Rev. Plant Biol. 62, 437-460. doi: 10.1146/annurev-arplant-42809-112312

Blokker, P., Yeloff, D., Boelen, P., Broekman, R. A., and Rozema, J. (2005). Development of a proxy for past surface UV-B irradiation: a thermally assisted hydrolysis and methylation py-GC/MS method for the analysis of pollen and spores. Anal. Chem. 77, 6026-6031. doi: 10.1021/ac050696k

Farman, J. C. (1977). Ozone measurements at British Antarctic Survey stations. Philos. Trans. R. Soc. Lond. B Biol. Sci. 279, 261-271.

Fraser, W. T., Scott, A. C., Forbes, A. E. S., Glasspool, I. J., Plotnick, R. E., Kenig, F., et al. (2012). Evolutionary stasis of sporopollenin biochemistry revealed by unaltered Pennsylvanian spores. New Phytol. 196, 397-401. doi: 10.1111/j.14698137.2012.04301.x

Fraser, W. T., Sephton, M. A., Watson, J. S., Self, S., Lomax, B. H., James, D. I., et al. (2011). UV-B absorbing pigments in spores: biochemical responses to shade in a high-latitude birch forest and implications for sporopollenin-based proxies of past environmental change. Polar Res. 30, 8312. doi: 10.3402/polar.v30i0.8312

Fraser, W. T., Watson, J. S., Sephton, M. A., Lomax, B. H., Harrington, G., Gosling, W. D., et al. (2014). Changes in spore c hemistry and appearance with increasing maturity. Rev. Palaeobot. Palynol. 201 41-46. doi: 10.1016/j.revpalbo.2013.11.001

Gupta, N. S., Michels, R., Briggs, D. E. G., Collinson, M. E., Evershed, R. P., and Pancost, R. D. (2007). Experimental evidence for the formation of geomacromolecules from plant leaf lipids. Org. Geochem. 38, 28-36. doi: 10.1016/j.orggeochem.2006.09.014
Hemsley, A. R., Barrie, P. J., and Scott, A. C. (1995). ${ }^{13}$ C Solid-state NMRspectroscopy of fossil sporopollenins - variation in composition independent of diagenesis. Fuel 74, 1009-1012.

Ineson, S., Scaife, A. A., Knight, J. R., Manners, J. C., Dunstone, N. J., Gray, L. J., et al. (2011). Solar forcing of winter climate variability in the Northern Hemisphere. Nat. Geosci. 4, 753-757. doi:10.1038/ngeo1282

Lomax, B. H., Fraser, W. T., Harrington, G., Blackmore, S., Sephton, M. A., and Harris, N. B. W. (2012). A novel palaeoaltimetry proxy based on spore and pollen wall chemistry. Earth Planet. Sci. Lett. 353-354, 22-28. doi: 10.1016/j.epsl.2012.07.039

Lomax, B. H., Fraser, W. T., Sephton, M. A., Callaghan, T. V., Self, S., Harfoot, M. et al. (2008). Plant spore walls as a record of long-term changes in ultraviolet-B radiation. Nat. Geosci. 1, 592-596. doi: 10.1038/ngeo278

Martin-Puertas, C., Matthes, K., Brauer, A., Muscheler, R., Hansen, F., Petrick, C., et al. (2012). Regional atmospheric circulation shifts induced by a grand solar minimum. Nat. Geosci. 5, 397-401. doi: 10.1038/ngeo 1460

Rozema, J. (2002). Toward solving the UV puzzle. Science 296, 1621-1622. doi: 10.1126/science. 1070024

Rozema, J., Noordjik, A. J., Broekman, R. A., Van Beem, A., Meijkamp, B. M., De Bakker, N. V. J., et al. (2001). (Poly)phenolic compounds in pollen and spores of Antarctic plants as indicators of UV-B: a new proxy for the reconstruction of past solar UV-B? Plant Ecology 154, 11-26. doi: 10.1023/A:1012913608353

Rozema, J., Van De Staaij, J., Björn, L.-O., and De Bakker, N. (1999). "Depletion of stratospheric ozone and solar UV-B radiation: evolution of land plants, UVscreens and functions of polyphenolics," in Stratospheric Ozone Depletion: The Effects of Enhanced UV-B Radiation on Terrestrial Ecosystems, ed J. Rozema (Leiden: Backhuys), 1-19.

Rozema, J., Van De Staij, J., Björn, L.-O., and Caldwell, M. (1997). UV-B as an environmental factor in plant life: stress and regulation. Trends Ecol. Evol. 12, $22-28$.

Rubenstein, C. V., Gerriene, P., de la Puente, G. S., Astini, R. A. and Steemans, P. (2010). Early Middle Ordovician evidence for land plants in Argentina (eastern Gondwana). New Phytol. 188, 365-369. doi: 10.1111/j.1469-8137.2010.03433.x Traverse, A. (2007). Paleopalynology. 2 Edn. Springer: Dordrecht.

Vandenbroucke, M., and Largeau, C. (2007). Kerogen origin, evolution and structure. Org. Geochem. 38, 719-833. doi: 10.1016/j.orggeochem.2007.01.001

Watson, J. S., Fraser, W. T., and Sephton, M. A. (2012). Formation of a polyalkyl macromolecule from the hydrolysable component within sporopollenin during heating/pyrolysis experiments with Lycopodium spores. J. Anal. Appl. Pyrol. 95, 138-144. doi: 10.1016/j.jaap.2012.01.019

Watson, J. S., Septhon, M. A., Sephton, S. V., Self, S., Fraser, W. T., Lomax, B. H., et al. (2007). Rapid determination of spore chemistry using thermochemolysis gas chromatography-mass spectrometry and micro-Fourier transform infrared spectroscopy. Photochem. Photobiol. Sci. 6, 689-694. doi: 10.1039/b617794h

Willis, K. J., Feurdean, A., Birks, H. J. B., Bjune, A. E., Breman, E., Broekman, R., et al. (2011). Quantification of UV-B flux through time using UV-B-absorbing compounds contained in fossil Pinus sporopollenin. New Phytol. 192, 553-560. doi: 10.1111/j.1469-8137.2011.03815.x

Conflict of Interest Statement: The authors declare that the research was conducted in the absence of any commercial or financial relationships that could be construed as a potential conflict of interest.

Received: 10 February 2014; accepted: 03 April 2014; published online: 22 April 2014. Citation: Fraser WT, Lomax BH, Jardine PE, Gosling WD and Sephton MA (2014) Pollen and spores as a passive monitor of ultraviolet radiation. Front. Ecol. Evol. 2:12. doi: $10.3389 /$ fevo.2014.00012

This article was submitted to Paleoecology, a section of the journal Frontiers in Ecology and Evolution.

Copyright (C) 2014 Fraser, Lomax, Jardine, Gosling and Sephton. This is an openaccess article distributed under the terms of the Creative Commons Attribution License (CC BY). The use, distribution or reproduction in other forums is permitted, provided the original author(s) or licensor are credited and that the original publication in this journal is cited, in accordance with accepted academic practice. No use, distribution or reproduction is permitted which does not comply with these terms. 